\title{
Student Teachers' and Experienced Teachers' Professional Vision of Students' Understanding of the Rational Number Concept
}

\author{
Maikki Pouta $^{1}$ - Erno Lehtinen ${ }^{1,2} \cdot$ Tuire Palonen $^{1}$
}

Published online: 28 May 2020

(C) The Author(s) 2020, corrected publication 2020

\begin{abstract}
The aim of this study was to investigate differences in student teachers' and experienced teachers' professional vision in natural settings and to elicit clues of the relation of in-themoment noticing and instruction quality of students' understanding of rational number concept. Rational number concept challenges both students and teachers because of natural number bias that learning of rational numbers is vulnerable to. Accurate professional vision and adequate instructions are needed to enhance students' understanding of rational number concept. Mobile eye-tracking technique enables video recording of natural teaching situations from a teacher's perspective with more specific information of teacher's in-the-moment noticing. Combined with cued retrospective reporting, this approach can gather more explicit evidence of teachers' professional vision and instructions. Results indicated that both student teachers and experienced teachers attended to mathematical and fraction-related aspect similarly but differed in interpreting and instructing students' fraction understanding. Student teachers made more advanced interpretations but their instructions were less adequate, whereas among experienced teachers, it was just the opposite. Furthermore, student teachers made more attempts to shared attention when using fraction understanding non-supporting instructions, whereas experienced teachers' attempts to shared attention were related to fraction understanding supporting instructions. Results indicate student teachers' difficulty to transfer pedagogical content knowledge from noticing to actions and experienced teachers to have more enhanced in-the-moment professional vision and its application to teaching. Practical implications for teacher training as well as methodological decisions of in-themoment professional vision studies in natural settings are discussed.
\end{abstract}

The study was implemented in collaboration with Turku Eye-Tracking Laboratories, University of Turku.

Electronic supplementary material The online version of this article (https://doi.org/10.1007/s10648-02009536-y) contains supplementary material, which is available to authorized users.

Maikki Pouta

maikki.pouta@utu.fi

1 Department of Teacher Education, Faculty of Education, University of Turku, Assistentinkatu 5, 20500 Turku, Finland

2 Vytautas Magnus University, Kaunas, Lithuania 
Keywords Professional vision · Instructions $\cdot$ Shared attention $\cdot$ Rational number concept $\cdot$ Mobile eye tracking

\section{Introduction}

Teacher's pedagogical content knowledge, mediated by individual instructing, is known to have a positive effect on students' learning (Baumert et al. 2010). Accurate noticing and knowledgebased reasoning, that is, professional vision (van Es and Sherin 2002), and its application are needed in order to transfer a teacher's pedagogical content knowledge into accurate instructions. These professional skills are particularly important when teaching demanding content knowledge that requires conceptual changes and novel ways of thinking. The fraction concept is known to be very challenging, not only for primary school students but also for teachers (Merenluoto and Lehtinen 2004) and for adults in general (Obersteiner et al. 2013; Vamvakoussi et al. 2012; Van Dooren et al. 2015); hence, teaching fractions offers a context for studying teachers' professional vision in which it is highly important that teachers are aware of students' thinking

Research has increased knowledge about differences in pre-service teachers' and experienced teachers' professional vision (e.g. Wolff et al. 2017), specifically in mathematics teaching (e.g. Jacobs et al. 2010), and in-the-moment noticing during mathematics instruction (e.g. Haataja et al. 2018). Studies have often been carried out in controlled laboratory settings (e.g. Stürmer et al. 2013b), in structured teaching situations (e.g. Stürmer et al. 2017) and/or by observing other teacher's teaching (e.g. Huang and Li 2012). However, increasing numbers of studies are using the advantages of new technology to study professional vision in authentic teaching settings (e.g. McIntyre 2016). Such research is needed to capture the diverse and complex process of teacher's professional vision in teaching situations when bare observations are not possible, but one needs to take action at the same time. Though the importance of professional vision for optimal instructing is reasoned in research, more empirical research is needed about how the quality of teachers' professional vision and the quality of instructing are related.

This study investigates in authentic settings the differences between student teachers' and experienced teachers' professional vision in recall situations, and aims to elicit clues about the relation between in-the-moment noticing and the quality of instructing students' understanding of the rational number concept.

\section{Teachers' Professional Vision}

Current educational research on teachers' noticing is partly based on Goodwin's (1994) definition of a professional vision meaning system, "which consists of socially organized ways of seeing and understanding events that are answerable to the distinctive interests of a particular social group" (p. 606). In education, professional vision has been conceptualised to consist of two components: selective attention and knowledge-based reasoning, which includes description, explanation and prediction (Seidel and Stürmer 2014). Therefore, the professional vision process includes integrated knowledge systems, and its development is strongly guided by teachers' knowledge and beliefs (Blomberg et al. 2011; Stürmer et al. 2013a; Wolff et al. 2016).

In education, professional vision has been applied by analysing teachers' noticing and interpretation of relevant features of classroom situations (van Es and Sherin 2002) and later expanded to include a third interrelated component: decision-making of action. However, these decisions do not always lead to effective actions because execution demands additional, 
complex skills (Jacobs et al. 2010.) Therefore, professional vision is not only an integrated model of a teacher's knowledge but also a system bridging knowledge and practice.

Developing students' thinking, rather than mere task completion, through accurate instructions requires in addition to noticing and interpretation of the details of students' thinking processes teacher's and student's shared attention on the same learning target (Mattinen 2006) and enough similar ways of attending to the target (Mason 2011). A dual eye-tracking study has revealed that shared attention, or noticing the absence of it, enables teacher to follow student's understanding and instruct student's learning process (Shvarts 2018); hence, shared attention in a teaching situation is important not only for accurate instructing but also for teacher's interpretations of student's understanding.

\section{Development of Teachers' Professional Vision}

Experience makes a remarkable difference in teachers' professional vision (Jacobs et al. 2010). Professional vision is not a natural talent that a teacher either has or lacks but, rather, it is a skill that can be learned and developed (Jacobs et al. 2010; Stürmer et al. 2016; Stürmer et al. 2013b). Good results have been accomplished when professional vision is fostered with guided video observations (Blomberg et al. 2013; Sherin and van Es 2009; Stahnke et al. 2016; Stockero et al. 2017; Stürmer et al. 2013b; Weber et al. 2018), though the impact on classroom practices needs further exploration (Major and Watson 2017).

Novice teachers do not automatically know how to observe students' learning (Stahnke et al. 2016; Star and Strickland 2008; Stockero et al. 2017). Eye-tracking studies have revealed that novice teachers tend to have more dispersed and image-driven perceptions, while expert teachers have more focused and knowledge-based perceptions (Wolff et al. 2016), can monitor more areas than novices (Wolff et al. 2016), focus on students (McIntyre et al. 2019; McIntyre et al. 2017; Stürmer et al. 2017; Van den Bogert et al. 2014), are more efficient in their noticing (McIntyre et al. 2017) and attend to essential features (Hogan et al. 2003; Miller 2011). This may be due to experts' capability to recognise quickly and accurately meaningful patterns in the situation (Berliner 2004). A key element of more effective noticing is being able to shift perspective from the teacher's actions to the students (Sherin and Han 2004).

Additionally, knowledge-based reasoning in classroom situations is more challenging for novice teachers (Stahnke et al. 2016). Novices who lack teaching experience tend to make statements rather than interpret understanding in respect of mathematical content (Star and Strickland 2008) and struggle with interpreting students' understanding (Jacobs et al. 2010; Wolff et al. 2017). Furthermore, novices tend to have more scattered and disjointed reasoning and fail to make connections between teachers' and students' actions, whereas expert teachers are able to adopt multiple points of view and integrate them while maintaining continuity of events (Wolff et al. 2015); hence, qualitative change in knowledge-based reasoning occurs when teachers use interpretation rather than description (van Es and Sherin 2008).

Differences also emerge in novice teachers' and expert teachers' instruction skills. Diagnostic teaching, which aims to build students' understanding, is a difficult skill to adopt and hence a feature of highly accomplished teachers (Shoenfelt 2011). According to Berliner (2004), teachers develop more holistic ways of seeing situations and their actions become increasingly flexible. These abilities do not develop by experience alone, since only a small group of teachers gain the skills of an expert (Berliner 2004.) Becoming an expert requires deliberate practice (Ericsson 2018). Teachers who repeatedly develop their skills with significant effort, concentration and motivation for self-improvement and who get immediate and 
informative feedback differ in their expertise from other experienced teachers (Bronkhorst et al. 2014.)

However, the definitions of concepts of expertise are used in varying ways. In professional vision studies, the term "novice teachers" refers to student teachers as well as to less experienced in-service teachers, whereas term "expert" is used to refer to experienced in-service teachers as well as in-service teachers with deliberately trained skills often nominated as experts by their colleagues. Of the participants of our study, we use terms "student teachers" and "experienced teachers", since the selection of participants is based on amount of teaching experience only.

\section{Professional Vision and Students' Understanding of Fractions}

Teaching rational numbers (fractions and decimals) is a challenge for teachers' professional vision, since noticing possible problems in students' mathematical thinking in rational number tasks is a demanding and complex process. Noticing in mathematics teaching in general is known to be challenging, especially for pre-service teachers, primary school teachers (Jacobs et al. 2010) and even for secondary mathematics teachers (Star and Strickland 2008) with comparably wider mathematical pedagogical content knowledge. Specifically, with the concept of rational numbers, it is challenging to notice and interpret students' misconceptions. At the same time, teachers need to inhibit their own possible misconceptions to be able to instruct students' understanding in an optimal way.

The difficulties in teaching and learning rational number knowledge are not only due to the increasing complexity of operations with fractions and decimals but also because the shift from natural to rational numbers requires deep changes in students' conceptions of numbers. Many of the features of natural numbers, such as size and order, are not directly applicable in thinking about rational numbers. However, increasing research evidence shows that students tend to overgeneralise their natural number knowledge to rational numbers (McMullen et al. 2015; Van Dooren et al. 2015; Vamvakoussi and Vosniadou 2004). This phenomenon, known as natural number bias, explains many of the difficulties that students have in understanding rational numbers and their operations (Van Dooren et al. 2015). Automatic activation of natural number knowledge in rational number tasks (natural number bias) happens for practically everybody (Obersteiner et al. 2013), and avoiding misconceptions and errors requires quick inhibition (Vosniadou et al. 2018). Studies have shown that conceptual change from natural to rational numbers is a long process, and natural number bias can result in misconceptions during many phases of the process (Kainulainen et al. 2017; McMullen et al. 2015).

This all means that noticing possible problems in students' mathematical thinking in rational number tasks is a demanding and complex process. Noticing of mathematical content in general is known to be challenging, especially for pre-service teachers, primary school teachers (Jacobs et al. 2010) and secondary mathematics teachers (Star and Strickland 2008) with comparably wider mathematical pedagogical content knowledge. Specifically, with the concept of rational numbers, noticing is challenged by students' natural number bias that causes crucial teaching moments that teachers should notice. At the same time, teachers need to inhibit their own natural number bias to be able to instruct students' understanding in an optimal way.

Furthermore, teachers' professional vision when teaching fractions can have crucial consequences for students' mathematical learning in general. Proficiency in fractions is a strong predictor of later mathematical learning (Siegler et al. 2013) and knowledge of fractions, decimals and percentages is highly important for professional and everyday skills (Hansen et al. 2017). However, research has shown that many students finish their general education 
with an inadequate understanding of rational numbers (Hansen et al. 2017; Van Dooren et al. 2015). This is partly due to deficiencies in primary school teachers' content knowledge and pedagogical content knowledge of rational numbers (Merenluoto and Lehtinen 2004; Newton 2008). To enhance students' learning of rational numbers, more focus should be put on teachers' professional skills and training. Hence, there is a need for research on teachers' professional vision when teaching rational numbers.

\section{Triangulation of Methods to Study Professional Vision}

Sherin and colleagues made initial attempts to obtain more accurate data for observing teacher-student interactions using a wearable video camera that was placed on a teacher's head (Sherin et al. 2008). Since this study, observation techniques have developed, and eye movement measurements have been found to be promising additional tools for professional vision studies (see McIntyre et al. 2017; McIntyre et al. 2019; Stürmer et al. 2017; Van den Bogert et al. 2014; Wolff et al. 2016); this has also been applied in mathematics (see Haataja et al. 2017, 2018). Furthermore, mobile eye tracking enables studies to take place in real teaching situations, which is important since teacher's noticing (Haataja et al. 2018), as well as interpretation and decision-making (Kaiser et al. 2017), is situation-specific. Besides capturing teacher's eye movements, eye tracking records teaching situations from a first-person perspective, which enables a more valid recall process by limiting observation to the essential and authentic parts of the interaction (Gaudin and Chaliés 2015).

However, the problem with eye tracking is that actual attention and its manner of expression cannot be derived from gaze alone (Mason 2011) neither does eye tracking catch the knowledge-based reasoning process of a teacher. To cover this gap, we use cued retrospective reporting (CRR). CRR employs video or other materials as a cue or stimulus for remembering a previous situation. Rather than being interviewed, participants in CRR are guided to remember and think aloud about the situation while watching the video. This enables more authentic remembering. Hence, CRR combines the advantages of concurrent reporting (which is impossible while teaching) with the advantages of retrospective recall (van Gog et al. 2005).

A challenge of CRR is balancing the proper amount of guidance to enable teachers to make notions but not to mislead or disturb their remembering process. A common problem with think-aloud tasks is teachers' tendency to focus on cue features other than those they are guided to focus on (Sherin and van Es 2009). Also, as close as CRR can get to teacher's attending, interpreting and decision-making during teaching situation, interaction between these components is more complex in real teaching situations than in CRR where observation is limited to some specific aspects (Sherin and van Es 2009), in this case to students' mathematical thinking.

This study aims to combine the methods of first-person perspective recording, eye tracking and CRR in order to investigate differences in student teachers' and experienced teachers' professional vision in authentic settings.

\section{Research Questions}

1. How do student teachers and experienced teachers differ in attending to students' mathematical thinking? 
2. How do student teachers and experienced teachers differ in interpreting students' understanding of fractions?

3. How do student teachers and experienced teachers differ in instructing students' understanding of fractions?

4. How do student teachers and experienced teachers differ in attempts at shared attention when instructing understanding of fractions?

\section{Methods}

\section{Participants}

Four student teachers, four experienced teachers and 82 fourth graders participated in the study. All student teachers (three female, one male) were in the final year of their class teacher studies. In the autumn of 2018, the student teachers participated in one of the alternative forms of conducting the final practical training period, which integrated research and teaching training. All of the student teachers only had teaching experience from three previous practical training periods within teacher education and some short periods as substitute teachers. In Finland, student teachers actively participate in teaching in practical training periods by planning and giving lessons under a class teacher's supervision. One of the student teachers had worked as a special needs assistant for 4 years before commencing her master studies. None of the student teachers had mathematics as a minor subject.

All experienced teachers (three female, one male) worked as fourth-grade class teachers in local elementary schools and had between 9 and 21 years of teaching experience. One of the experienced teachers had studied mathematics as a minor subject during class teacher studies; one had completed in-service mathematics teaching courses during her career but had not taught mathematics for 10 years; and one had completed special education studies but had not worked as a special education teacher. Each experienced teacher supervised one student teacher's training period.

In all, 82 fourth-grade students from four classes participated in the lessons and video recordings. Class sizes varied between 11 and 27 students. Participation was voluntary for all, and written consent was required from students' custodians. Only three students' custodians declined their children's participation in the research. Students who did not have permission for participation did not take part in video recordings. Experienced teachers received compensation in accordance with their salary for the time spent on research measurements.

\section{Procedure}

Ethical clearance from ethics committee was obtained and the committee supported implementation of the study. Data gathering was done during the autumn term of 2018. Measurements were taken for experienced teachers before the student teachers' training period. For student teachers, measurements were taken in the first lesson they led on their own, after $8 \mathrm{~h}$ of observation of the class.

Teachers and their students were familiarised with the eye-tracking glasses at the end of the previous lesson for about $15 \mathrm{~min}$ before the first recording commenced. The mathematics lesson was recorded with eye-tracking glasses and the CRR was carried out after the video recording. 


\section{Measures}

Data was gathered similarly from both student teachers and experienced teachers. Each teacher carried out one lesson that she/he recorded with the wearable eye tracker. Teachers were instructed to deliver a 45-min lesson about fractions and to pick a specific topic that would be suitable for their students. No other instructions about the lesson were given. In all, $5 \mathrm{~h}$ of video data of teaching situation was gathered, with each recording lasting $38 \mathrm{~min}$ on average. The recording of one participant stopped due to errors with the wireless connection, which happened twice, causing the loss of about 7 min of data.

In order to study what aspects the teachers noticed and interpreted in the students' learning, each teacher participated in CRR after the recorded lesson. Teachers were instructed to watch the video of the lesson and think aloud about what they noticed regarding students' mathematical thinking and how they decided to instruct students during the lesson. Teachers were allowed to talk during the video and to pause it if they needed to. To ensure that recall of the teaching situation was as authentic as possible, we used scene video that did not include eyetracking data and the researcher did not comment or ask questions during the CRR. The CRR lasted on average for $54 \mathrm{~min}$, with the shortest taking $38 \mathrm{~min}$ and the longest taking $82 \mathrm{~min}$.

\section{Eye-Tracking Equipment}

The wearable Tobii Pro Glasses 2 mobile eye tracker consists of a head unit resembling regular glasses that are connected with a thin cable to a recording unit attached to the participant's hip with a belt. The glasses include four eye cameras with $240 \times 960$ resolution to record eye movements, a microphone and a scene camera with $1920 \times 1080$ at $25 \mathrm{fps}$ and a wide field of view $\left(90^{\circ}\right)$ to record the environment. The eye tracker catches data with a $50 \mathrm{~Hz}$ sampling rate. The glasses have an automatic slippage compensation system to avoid loss of calibration during dynamic recording. The calibration system is one-pointed, and all participants were calibrated before recording and before starting a new recording after interruption due to technical error. The system is wirelessly connected to a computer, where recording is controlled with the Tobii Pro Glasses Controller (× 64). (Tobii 2016).

\section{Data Analysis}

Without being given any instructions about teaching methods, all teachers had quite similar structures to their lessons. The teachers first started with a general overview of the topic, followed by individual, pair or group work when teachers checked how students proceeded. Most of the teachers arranged workbook tasks for the students. One student teacher and one experienced teacher teaching the same class had playful tasks with demonstrative materials. To identify the quality of the individual support, parts of one-on-one teaching for individual students, pairs or small groups were selected for analysis. Durations of selected phases varied from 11 to $30 \mathrm{~min}$. Selection of episodes continued based on the qualitative analysis described in Fig. 1.

First, the teacher's speech during the CRR was transcribed. Next, from all episodes, those including teachers' notions about students' mathematical thinking in the CRR were identified and selected for later analysis. Analysis included two categories: mathematical category with episodes in which a teacher referred to a student's mathematical thinking, and nonmathematical category with episodes in which a teacher noted things other than a student's 


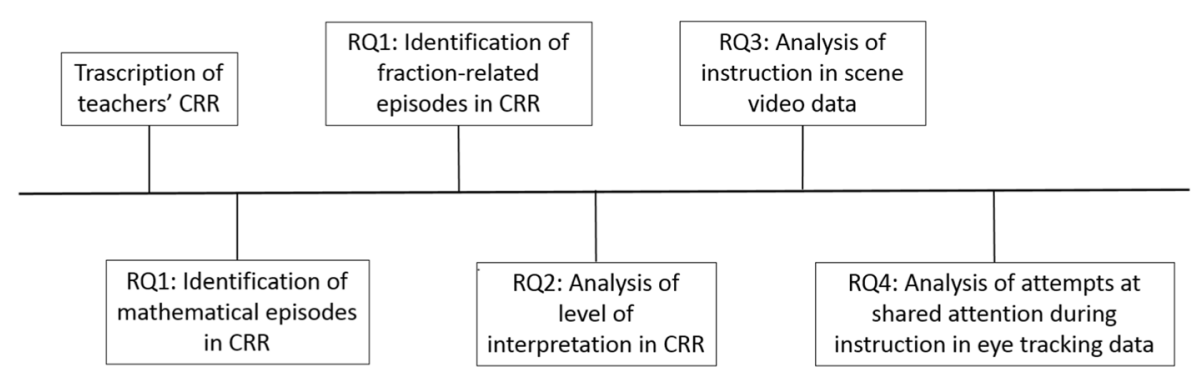

Fig. 1 Procedure of analysis

mathematical thinking. Analysis was done based on the transcripts, and video was used as a secondary source to identify whether a teacher referred to the task or mathematical content.

Next, teachers' notions of students' understanding of fractions in the CRR were identified and selected for later analysis. Analysis included two categories. Category of fraction-related content included episodes in which a teacher refers to a student's understanding of fractions. Category of other mathematical content included episodes in which a teacher mentions something general about an individual student's mathematical understanding. Analysis was done based on the transcripts, and video was used as secondary source to confirm the target of teacher's notion.

To analyse teachers' interpretations of students' understanding of fractions, the qualitative analysis similar to van Es and Sherin's (2008) study was carried out for fraction-related episodes. Three levels were used and modified based on our data: descriptive, evaluative and interpretive. An episode was coded as "descriptive" if the teacher described what the student was doing but did not evaluate or interpret the student's understanding of fractions. An episode was coded as "evaluative" if the teacher not only described what the student did but also evaluated the difficulty of the task for the student but did not interpret the student's thinking. An episode was coded as "interpretive" if the teacher made detailed fraction contentrelated notions about the student's understanding and reasoned it. Episodes were coded based on the highest possible level because teachers first tend to make general notions and then specify their talk. Analysis was done based on transcripts, and video was used as secondary source to identify whether a teacher referred to task or fraction content.

Next, teachers' instructions were analysed for all fraction episodes from the video data. Two categories were used. Fraction understanding supportive episodes included a teacher's instruction that mainly aimed to deepen students' understanding of a fraction concept. Fraction understanding non-supportive episodes included teacher's instructions that were mainly misleading, superficial, did not challenge students' own thinking or supported natural number bias. Classification of instruction was based on what kinds of instructions were most present in the episode.

All phases of analysis described above were double coded by trained analysers. Of each dataset, 20-25\% of episodes were selected for double coding by selecting every fifth episode of the data set. Inter-rater reliability for each phase was between $79 \%$ and $86 \%$. Differences in coding were resolved through discussion. More detailed information of the categories of the qualitative analysis is provided in Appendix 1.

Eye movement data was used to analyse teachers' shared attention. Because of the dynamic nature of our data, times of interest (TOIs) were used as an analysis tool, involving manually marking time points (events) in the data when the teacher's gaze was in an area of interest 
(AOI). Three AOIs were identified as custom TOIs: material (AOI 1); student (AOI 2); and other (AOI 3, meaning a teacher's gaze was at any area other than the material or student(s)). AOIs are visualized in Fig. 2.

Each TOI was built by two events: the starting point and the ending point of the AOI. Next, sequences of gaze shifting from the material to a student's face and back to the material were defined as attempts at shared attention. The frequency of attempts at shared attention was counted and the relation to instructing was studied with cross tabulation analysis.

For the recording that suffered from problems with the wireless connection, unsuccessful calibration caused the loss of $7 \mathrm{~min}$ of eye movement data covering two fraction episodes. This part was left out from the eye movement analysis. The quality of eye tracking for other parts of the data was good, with 78-96\% gaze samples. Minor loss of gaze samples was mainly due to participants looking above or below the rim of the glasses. Analysis was done with Tobii Pro Lab using gaze filter Tobii I-VT (attention), which is designed for analysis of eye tracking in dynamic situations. Filter velocity threshold was set to $100 \%$ s to define fixations, smooth pursuit, vestibular ocular reflex and 10-15\% of saccades as indicators of attention (Tobii Pro 2019).

\section{Results}

\section{Differences in Student Teachers' and Experienced Teachers' Attending to Students' Mathematical Thinking}

We were interested to see what amount of teachers' notions in the CRR were related to mathematical content and, more specifically, to fraction content. Table 1 shows the amount of student teachers' and experienced teachers' notions made in the CRR. All episodes include notions of students' mathematical thinking and other non-mathematical notions of teaching

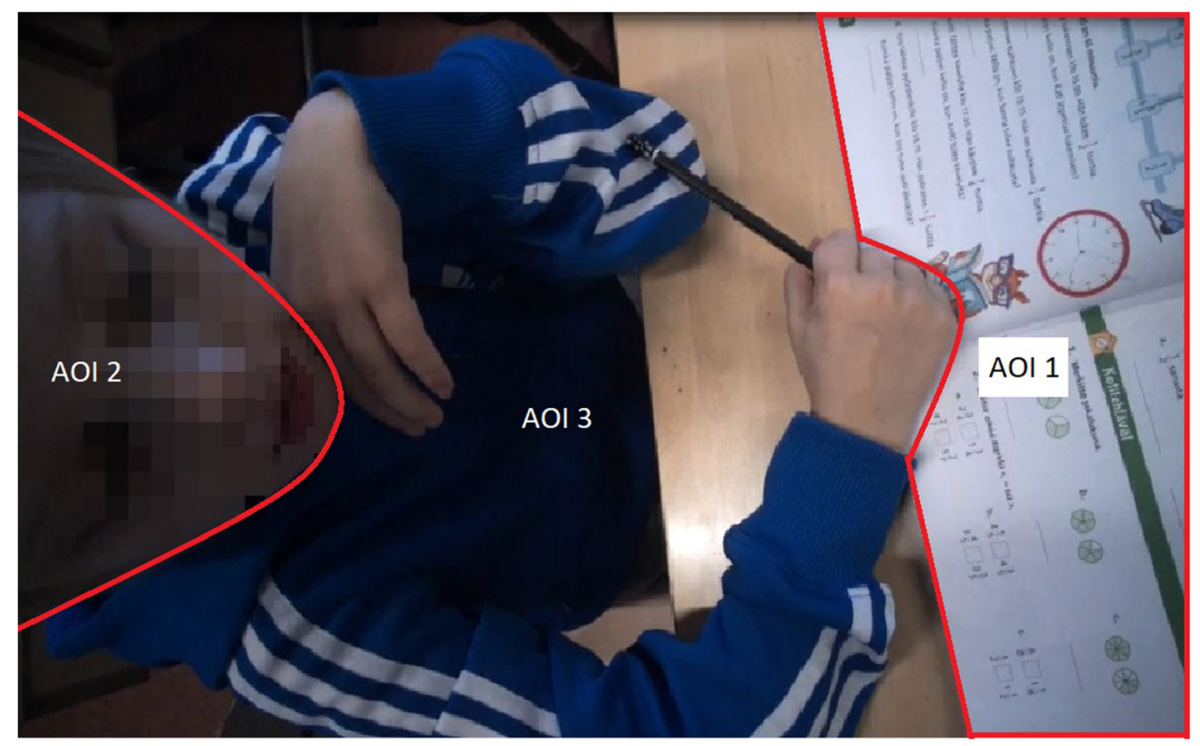

Fig. 2 Example of areas of interest 
situations. Episodes that focused on students' mathematical thinking include notions of students' fraction understanding and notions of other mathematical content.

Student teachers and experienced teachers attended to both mathematical aspects in students' learning and other features of their learning. There was no significant difference in student teachers' and experienced teachers' selection of mathematical and non-mathematical episodes, $\chi^{2}(1, N=152)=1476$. Also, selection of fraction-related and other mathematical content-related episodes did not differ between student teachers and experienced teachers, $\chi^{2}$ $(1, N=86)=3285$.

\section{Differences in Student Teachers' and Experienced Teachers' Interpretation of Students' Understanding of Fractions}

Furthermore, we were interested in how teachers interpreted students' understanding of fractions and whether there were qualitative differences in their ways of commenting on these situations. Table 2 shows student teachers' and experienced teachers' level of interpretation of students' understanding of fractions in the CRR.

Student teachers' notions were mostly interpretative $(27.3 \%)$ and evaluative $(63.6 \%)$, whereas experienced teachers' explanations were predominantly evaluative $(41.7 \%)$ and descriptive $(44.4 \%)$. The difference in interpretation levels was significant, $\chi^{2}(2, N=69)=$ $10.93, p<0.01$.

\section{Differences in Student Teachers' and Experienced Teachers' Types of Instructing Students' Understanding of Fractions}

We were also interested in how student teachers' and experienced teachers' noticing and interpretation transferred into instruction and whether there were differences between the groups. Table 3 describes student teachers' and experienced teachers' instructions.

Student teachers attended to episodes classified as supportive only in $21.2 \%$ of episodes, whereas experienced teachers attended to episodes classified as supportive in $52.8 \%$ of episodes. The difference was significant, $\chi^{2}(1, N=69)=7.306, p<0.01$. As described earlier, student teachers tend to interpret and evaluate the episodes they made notions on, and as can be seen from Table 3, these interpretations and evaluations were mostly about fraction understanding in non-supportive teaching situations. This indicates that student teachers aimed at evaluating and interpreting students' understanding of fractions, which requires knowledge of fraction content learning, but they could not transfer their knowledge adequately into instruction.

Table 1 Notions of one-to-one teaching situations

\begin{tabular}{lll}
\hline & Student teachers & Experienced teachers \\
\hline All episodes & $100.0 \%(59)$ & $100.0 \%(93)$ \\
Non-mathematical & $37.3 \%$ & $47.3 \%$ \\
Mathematical & $62.7 \%$ & $52.7 \%$ \\
Fractions & $55.9 \%$ & $38.7 \%$ \\
Other mathematical content & $6.8 \%$ & $14.0 \%$ \\
\hline
\end{tabular}


Table 2 Levels of interpretation in fraction understanding-related episodes

\begin{tabular}{lll}
\hline & Student teachers & Experienced teachers \\
\hline All fraction episodes & $100.0 \%(33)$ & $100.0 \%(36)$ \\
Interpretive & $27.3 \%$ & $13.9 \%$ \\
Evaluative & $63.6 \%$ & $41.7 \%$ \\
Descriptive & $9.1 \%$ & $44.4 \%$ \\
\hline
\end{tabular}

An example from one student teacher clarifies the interpretation in the CRR and nonsupportive instructing. The student teacher explained to the student how the mixed fraction 1 $3 / 10$ should be written. The student did not understand how the whole unit should have been marked but was able to alter one whole as 10 over 10. Instead of instructing the student to understand that 10/10 means one whole, the student teacher instructed the student to mark the numbers that were given in the task. In the CRR, the student teacher pointed out that he had noticed the student's understanding and interpreted the mathematical content the student was operating with during the task: "I kind of noticed that she understands, like, the relation of the fraction and the whole number when she altered that number one as 10 over 10 even though it was not kind of what was meant [to be done]".

As described earlier, experienced teachers tend to describe and evaluate the episodes they made notions on. As can be seen from Table 3, these descriptions and evaluations were more evenly distributed to fraction understanding supportive and non-supportive episodes. This indicates that, even though experienced teachers struggled with interpreting students' understanding of fractions, in many of these situations, they could still support students' understanding of fractions.

An example from one experienced teacher clarifies the description in the CRR and supportive instructing. The experienced teacher explained to the student that he could solve the task by thinking of fractions as divisions. She phased the task by asking questions that helped the student to transfer fractions as whole numbers and understand the relation of fractions and divisions. During the CRR, the teacher described at a general level how students think about these kinds of tasks and how she guided them to understand that, but she did not evaluate or point out the thinking of this particular student: "Divisions are often, like, which way the student thinks that. Someone thinks that how many times the number fits in the other number or does one think how many times that 15 , like, there are two ways to think about it. How many parts it divides or how many times it fits so that usually I tell both of these options to a child because then the one that is easier for him to start thinking. Which way, like, as multiplication or by dividing".

Table 3 Categories of instructing in fraction-related episodes

\begin{tabular}{lllll}
\hline & Interpretive & Evaluative & Descriptive & Sum \\
\hline Student teachers & & & & $21.2 \%(7)$ \\
Supportive & $6.1 \%$ & $12.1 \%$ & $3.0 \%$ & $78.8 \%(26)$ \\
Non-supportive & $21.2 \%$ & $51.5 \%$ & $6.1 \%$ & $52.8 \%(19)$ \\
Experienced teacher & & & & $19.4 \%$ \\
Supportive & $11.1 \%$ & $22.3 \%$ & $25.0 \%$ & $47.2 \%(17)$ \\
Non-supportive & $2.8 \%$ & $19.4 \%$ & & \\
\hline
\end{tabular}




\section{Student Teachers' and Experienced Teachers' Differences in Attempts at Shared Attention During Instruction of Fraction Understanding}

Furthermore, we were interested to investigate whether student teachers and experienced teachers differed in the amount of attempts at shared attention during instruction. Table 4 describes student teachers' and experienced teachers' attempts at shared attention during fraction-related episodes.

There was only a small overall difference in the number of student teachers' $(N=95)$ and experienced teachers' $(N=86)$ eye movements indicating attempts at shared attention. However, student teachers indicated more shared attention in fraction understanding nonsupportive episodes and experienced teachers in fraction understanding supportive episodes. The difference was significant, $\chi^{2}(1, N=184)=41.97, p<0.001$.

The results indicate qualitative differences between student teachers' and experienced teachers' instructing. Both student teachers and experienced teachers made attempts at shared attention but they differed with the target they tried to attend the students to. Experienced teachers' attempts at shared attention were mainly part of instruction episodes in which they were supporting students' understanding of fractions. Student teachers' instruction episodes were mainly classified as non-supportive (78.8\%), and attempts at shared attention were distributed correspondingly. Experienced teachers tended to focus students' attention on essential features of the task to enhance conceptual learning, whereas student teachers tended to focus students' attention on irrelevant or even misleading features of the task.

\section{Discussion}

The aim of this study was to investigate student teachers' and experienced teachers' professional vision when teaching rational numbers in authentic teaching situations. The study focused on student teachers' and experienced teachers' differences in attending to mathematical aspects of teaching situations, in their interpretation of students' understanding of fractions, in the types of instructional support and in attempts at shared attention in episodes they attended to. Even though the small sample size limits generalisations about the results, the qualitative findings based on the data provide insights into teachers' noticing and interpretation of students' understanding of rational numbers. Results indicate that student teachers are already quite advanced in noticing and interpreting students' learning processes, but experienced teachers can better apply their knowledge in supporting students' learning of this demanding mathematical content.

Table 4 Amount of teachers' attempts at shared attention during instruction

\begin{tabular}{lll}
\hline & Student teachers & Experienced teacher \\
\hline All shared attention & $100.0 \%(95)$ & $100.0 \%(86)$ \\
Supportive & $27.0 \%$ & $76.0 \%$ \\
Non-supportive & $73.0 \%$ & $24.0 \%$ \\
\hline
\end{tabular}


The results indicate that there were no differences in student teachers' and experienced teachers' attending to students' mathematical thinking or fraction understanding in the CRR. Aligning with previous studies (Sherin and van Es 2009; van Es and Sherin 2008), both student teachers and experienced teachers also tended to focus on other than mathematical features of teaching situation even when they were guided to focus on mathematical aspects. This indicates that even subject-specific noticing includes general students' learning and classroom management-related aspects.

Furthermore, the results indicate that, in the CRR, student teachers interpreted students' understanding of fractions in addition to evaluating it, whereas experienced teachers tended to describe and evaluate students' understanding of fractions, which is contradictory to previous studies (Jacobs et al. 2010; Star and Strickland 2008). This result may be due to the more recent mathematics education studies of student teachers which enables them to make content-specific interpretations. Experienced teachers tend to tell how students usually operate, so their knowledge of individual students might have, in some cases, overshadowed their specific interpretations about fraction learning.

Student teachers and experienced teachers differed in their focus of instruction which triggered teachers' interpretations in the CRR. Student teachers selected more non-supportive episodes than supportive episodes, whereas experienced teachers selected equally fraction understanding supportive episodes and non-supportive episodes. Even though student teachers had more advanced interpretations in the CRR relating to fraction episodes, most of these episodes included non-supportive instructing of students' understanding of fractions. This indicates that student teachers are able to use their content knowledge to interpret students' understanding of fractions but struggle with applying it to instructions, which is known to demand other complex skills (Jacobs et al. 2010). It is also possible that student teachers were able to interpret students' understanding afterwards in the CRR but were not able to do it during the teaching situation, which demands more selective noticing (Sherin and van Es 2009), whereas experienced teachers were able to apply it in some teaching situations but struggled to interpret students' thinking in the CRR. It is notable that this study focuses on the relation of interpretation skills and instruction skills, which demands the selection of episodes based on teachers' interpretations in the CRR among all one-on-one teaching situations; hence, further analysis is needed to study what the main trend in teachers' instructing of rational number knowledge was.

Analyses of attempts at shared attention reveal features of relations between noticing, interpreting and instructing. Even though student teachers and experienced teachers made as many attempts at shared attention with students, there are qualitative differences. Student teachers tended to focus students' attention on irrelevant or even misleading features of the fraction task, whereas experienced teachers aimed at focusing students' attention on essential features that enhanced their conceptual understanding of fractions. Studies have shown that, in parent-child interaction, shared attention enables parents to interpret and instruct children (Shvarts 2018). For student teachers, attempts at shared attention might have enabled them to interpret students' understanding but did not lead to accurate instructing, which indicates the diagnostic nature of student teachers' noticing. In contrast, experienced teachers' attempts at shared attention were related to accurate instructions, which indicates 
more advanced noticing despite difficulties in interpreting students' understanding after the teaching situation.

By using the advantages of mobile eye tracking, this study combined first-person perspective recording, eye tracking and CRR with minimised researcher interference during the data-gathering process to foster authenticity of the teaching situation. We used scene video as a basis for CRR to provide identical perspectives to the teaching situation and to focus teachers' attention on students' thinking in real one-on-one teaching situations (Sherin and Han 2004). Free recall, without interview questions, enabled participants to recall their thinking during the teaching situation and to express their thinking about the situations they found to be meaningful. Fostering ecologically valid settings makes it impossible to standardise conditions and exclude the effect of other possible factors for human behaviour. This inevitably sets limits for comparisons between groups, but it enables studying teachers' professional vision, as complex as it is, in buzzing teaching situations.

\section{Implications}

The results of this study indicate that both student teachers and experienced teachers would benefit from training in professional vision and instruction skills relating to students' understanding of fractions, but their need for training is different. Our results indicate that student teachers would benefit from training regarding their inthe-moment noticing and interpretation skills as well as instruction skills in order to be able to apply the knowledge they used in the CRR. Even though these skills, based on our results, develop through teaching experience, guided video enhanced training, for example, would be beneficial (Blomberg et al. 2013; Sherin and van Es 2009; Stahnke et al. 2016; Stockero et al. 2017; Stürmer et al. 2013a, b; Weber et al. 2018).

Unlike student teachers, experienced teachers would benefit from enhancing mathematical pedagogical content knowledge of rational numbers in order to deploy more accurate noticing than they presently do to interpret students' fraction understanding in more detail and instruct students' understanding even better.

Applying mobile eye-tracking technology in teacher training could help teachers to focus on students' thinking processes rather than their own actions, which has been found to be essential for more effective noticing (Sherin and Han 2004). Further investigations are needed to study the adequacy of these research methods as tools for teacher training. In the future, a similar design study with a bigger sample would provide results that can be generalised. Findings about the benefits and limitations of the methods we used in this study provide information for designing studies of in-themoment noticing in authentic settings.

Funding Information Open access funding provided by University of Turku (UTU) including Turku University Central Hospital.

\section{Compliance with Ethical Standards}

Conflict of Interest The authors declare that they have no conflict of interest. 


\section{Appendix}

\begin{tabular}{lll}
\hline Analysis & Indicators & Examples \\
\hline
\end{tabular}

\section{Identification of mathematical and nonmathematical episodes}

Mathematical episodes Teacher refers to a student's mathematical thinking.

\section{Non-mathematical episodes}

Identification of fraction related and other mathematical content related episodes

\section{Fraction-related}

Teacher refers to student's fraction
Uses mathematical terms or indirectly refers to a student's mathematical thinking.

Mentions a student's skills in mathematics.

Tells how she/he did/did not understand a student's thinking.

Tells how he/she guided a student's mathematical thinking.

Talks mostly about other things but still briefly refers to a student's mathematical thinking.

Tells how a student solves a mathematical problem.

Mentions that a student understands/does not understand mathematical content.

Mentions that a student can/cannot solve the mathematical task.

Mentions what strategies a student uses to solve mathematical problem.

Notes something about a student's mathematical learning.

Tells how the mathematics task helped a student to understand mathematics.

"Here we talked about how to operate with the number line."

"There was no problem, she is usually good at mathematics."

"I don't know why he got that for an answer."

"I tried to draw a picture to make the fraction more clear to the student."

"The task included different kind of problem solving that is tricky for the students. And she has problem with concentrating on the task. But there she got the idea and was able to put the right denumerator."

"He had understood that demoninator should be always the same, but I asked him to pay attention to the amount of the parts of the fraction pie."

"She did not understand how the whole should have been divided in parts."

"He had not been able to proceed with the task."

"She uses the picture of the textbook to solve the problem."

"He had gotten three for an answer which was not right but it did not disturb his learning."

"This was a good task because it includes a bit different expression for the same fraction so they have to learn these different meanings and it can be quite difficult for many."

Teacher notes things other than a student's mathematical thinking.

Notes things other than a student's mathematical thinking.

Notes unspecified group's mathematical thinking.

Notes a student's behaviour or learning in general.

Notes unspecified groups' working.

Comments the difficulty of the task.

Comments something unrelated to students' learning.

Tells how she/he guided students work but does not refer to a student's mathematical thinking.

Reflects their own teaching or task.
"They are a bit too energetic to concentrate properly.'

"Students are usually pretty good at this kind of mathematical tasks."

"This is learning nowadays."

"They are proceeding well with the task."

"This can be challenging for many students since the task demands an other kind of problem solving."

"I noticed that my clock stopped working."

"I encouraged the student and told him that the task is quite difficult."

"I should have checked more how students proceed. I know that many of them are uncertain." related understanding 
(continued)

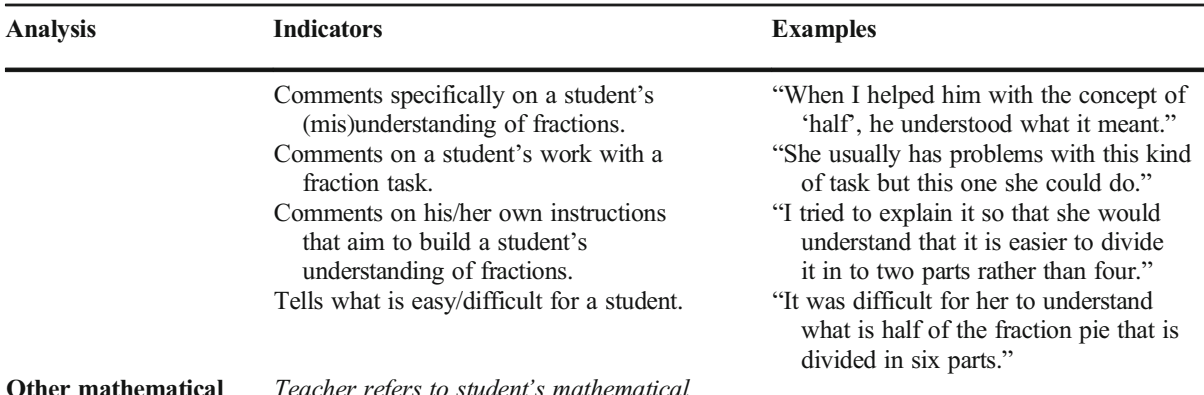

\section{Other mathematica content related}

\section{Teacher refers to student's mathematical} understanding in general

Mentions something general about an individual student's mathematical understanding.

Refers to a student's skills with mathematical content other than fractions.

Mentions what kind of strategy she/he taught to a student.

Notes a student's task-completing or strategies.

\section{Analysis of level of interpretation}

\section{Descriptive}

Evaluative

Interpretive

Teacher describes what the student is doing but does not evaluate or interpret the student's understanding of fractions.

Comments unspecifically about a student's understanding.

Makes fraction-related comments about the task rather than a student's understanding.

Describes her/his guidance without mentioning a student's thinking.

Makes general notions about fraction learning.

Comments the fraction tasks.

Evaluates the whole group's or part of the group's understanding.

Notes a student's (mis)understanding, but does not reason it.

Teacher does not only describe what the student is doing but also evaluates the difficulty of the task for the student but does not interpret the student's thinking.

Comments the difficulty of fraction tasks for a student without interpretation.

Makes unspecified interpretations about fraction content.

Evaluates a student's understanding of fractions with explanation that was not related to understanding of fractions.

Teacher makes detailed fraction content-related notions about the student's understanding and reasons it.

"He is really good at mathematics."

"She could not remember how to operate with multiplications."

"I taught him to compare the pictures to figure out the solution to this problem."

"Here she marked with dots how many parts she had already counted."

"He lacks skills in maths but it was nice to see that he could get started with this task."

"She had done a comparison of amounts but I don $\mathrm{t}$ know how they really managed."

"I reminded him about the rules relating $\mathrm{t}$ o reducing; that is important to remember in future."

"In fractions one must understand which one is the denominator and which one is the numerator."

"I am glad I took this task where one has to think about the order of fractions in the number line."

"They could do these fraction tasks well."

"She had wrong denominator but it did not matter."

"This was easy for him."

"There she draws the amount of the numerator - odd. She probably needed a concrete model of the situation."

"She had not made any extra marks to the task so she must have known how to solve it." 
(continued)

\begin{tabular}{ll}
\hline Analysis & Indicators \\
\hline Interprets a student's understanding. \\
\\
Comments a student's understanding \\
with reference to a student's actions. \\
Makes specific description with fraction \\
understanding-related notions about a \\
student's task solving.
\end{tabular}

Analysis of teachers' instructions

Fraction
understanding
supportive

Teacher uses instructions that mainly aim to deepen students' understanding of a fraction concept.

Encourages students to think him/herself by asking a question or modelling the situation but not giving the solution.

Ensures the student's understanding by fraction content-related questions.

Phases the task by asking fraction content-related questions.

\section{Fraction \\ understanding nonsupportive}

Analysis of shared attention

Teacher's instructions are mainly misleading or superficial, do not challenge students' own thinking, or instructions support natural number bias.

Provides general guidance, such as questions about students proceeding with a task.

Guides task performance rather than understanding of fraction content.

Guides in a superficial way.

Tells the right answer to the student.

Phases the task by giving the answers.

Asks rhetorical questions.

Quizzes about the right answer.

Gives misleading or natural number bias-supporting guidance by passing a student's misconception.

Gives misleading or natural number bias-supporting guidance by guiding students to use the same strategies with fractions as with natural numbers.

Material

TOI was built by two events: the starting point of material AOI when teacher's

\section{Examples}

"He counted the fraction wrong because he counted the marks in the number vline, not the amount of parts between marks."

"He understood what a whole number means as a fraction because he could transform it."

"First he wrote down the fractions based on the picture. Then he modified it to a mixed number. He could explain why these had the same denominators when I asked and then compared the numerators to be able to mark them in the number line."

"How many parts should I divide this according to the task description? Yes, three." (Draws lines to fraction pie)

"What is the numerator here? And denominator?"

"How would you say this fraction? One over two, yes. And how about this? Two over four, yes. And what do you notice? Exactly! They are the same size."

"How is it going?"

"Here you could have marked the answer of each phase."

"Just do the way you did in the previous task."

"Then mark number one here and then three on the top and five under the line."

"Here you draw two lines. Then you get quarters. And then colour two of it and you get two over four, that is half."

"There is more than in here, right?"

"Is the answer one over three? Is it three over three? Is it two over three? Yes, mark that."

When a student points out that $4 / 8$ is bigger than $2 / 4$ because of the bigger denominator, the teacher tells that they are equal and continues to the next task without explaining why they are equal.

When a teacher guides a student to ignore the denominator that is the same for all fractions in the task and fill the number line like it includes natural numbers. 
(continued)

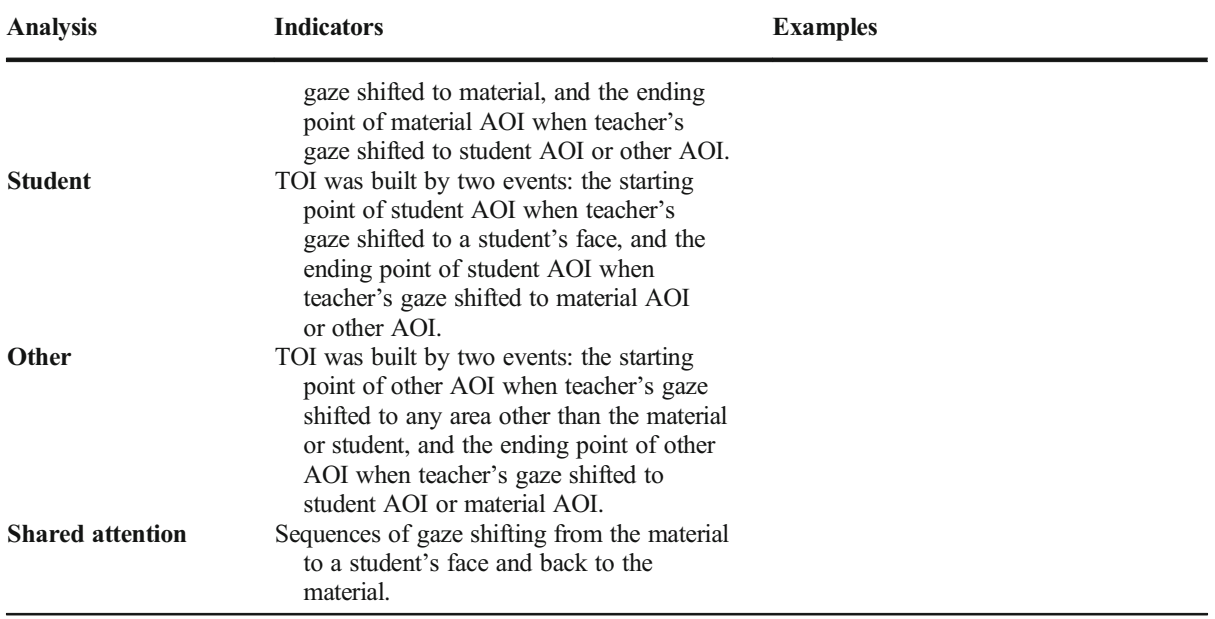

Open Access This article is licensed under a Creative Commons Attribution 4.0 International License, which permits use, sharing, adaptation, distribution and reproduction in any medium or format, as long as you give appropriate credit to the original author(s) and the source, provide a link to the Creative Commons licence, and indicate if changes were made. The images or other third party material in this article are included in the article's Creative Commons licence, unless indicated otherwise in a credit line to the material. If material is not included in the article's Creative Commons licence and your intended use is not permitted by statutory regulation or exceeds the permitted use, you will need to obtain permission directly from the copyright holder. To view a copy of this licence, visit http://creativecommons.org/licenses/by/4.0/.

\section{References}

Baumert, J., Kunter, M., Blum, W., Brunner, M., Voss, T., Jordan, A., ... Tsai, Y.-M. (2010). Teachers' mathematical knowledge, cognitive activation in the classroom, and student progress. American Educational Research Journal, 47(1), 133-180. doi: https://doi.org/10.3102/0002831209345157.

Berliner, J. (2004). Expert teachers: their characteristics, development and accomplishments. Retrieved from https://pdfs.semanticscholar.org/0b95/2838f63fca8f43661a1fc8bdea1238ec67d4.pdf.

Blomberg, G., Stürmer, K., \& Seidel, T. (2011). How pre-service teachers observe teaching on video: effects of viewers' teaching subjects and the subject of the video. Teaching and Teacher Education, 27(7), 1131-1140. https://doi.org/10.1016/j.tate.2011.04.008.

Blomberg, G., Renkl, A., Gamoran Sherin, M., Borko, H., \& Seidel, T. (2013). Five research-based heuristics for using video in pre-service teacher education. Journal for Educational Research Online, 5(1), 90-114.

Bronkhorst, L. H., Meijer, P. C., Koster, B., \& Vermunt, J. D. (2014). Deliberate practice in teacher education. European Journal of Teacher Education, 37(1), 18-34. https://doi.org/10.1080/02619768.2013.825242.

Ericsson, K. A. (2018). The differential influence of experience, practice, and deliberate practice on the development of superior individual performance of experts. In K. A. Ericsson, R. R. Hoffman, A. Kozbelt, \& A. M. Williams (Eds.), Cambridge handbooks in psychology. The Cambridge handbook of expertise and expert performance (pp. 745-769). New York: Cambridge University Press.

Gaudin, C., \& Chaliés, S. (2015). Video viewing in teacher education and professional development: a literature review. Educational Research Review, 16, 41-67.

Goodwin, C. (1994). Professional vision. American Anthropologist, 96(3), 606-633.

Haataja, E., Salminen-Saari, J., Laine, A., Huotilainen, M., McIntyre, N., Hannula, M., ... Garcia Moreno-Esteva, E. (2017). Exploring collaboration during mathematics problem solving in the classroom with multiple mobile eye tracking. Utrecht: Utrecht University.

Haataja, E., Garcia Moreno-Esteva, E., Toivanen, M., \& Hannula, M. S. (2018). Teacher's gaze behavior when scaffolding peer interaction and mathematical thinking during collaborative problem-solving activity. In E. Bergqvist, M. Österholm, C. Granberg, \& L. Sumpter (Eds.), Proceedings of the 42nd Conference of the 
International Group for the Psychology of Mathematics Education, 2 (pp. 475-482). Umeå, Sweden: PME International Group for the Psychology of Mathematics Education.

Hansen, N., Jordan, N. C., \& Rodrigues, J. (2017). Identifying learning difficulties with fractions: a longitudinal study of student growth from third through sixth grade. Contemporary Educational Psychology, 50, 45-59.

Hogan, T., Rabinowitz, M., Craven III, J. A., \& J, T. (2003). Representation in teaching: inferences from research of expert and novice teachers. Educational Psychologist, 38(4), 235-247. https://doi.org/10.1207 /S15326985EP3804 3

Huang, R., \& Li, Y. (2012). What matters most: a comparison of expert and novice teachers' noticing of mathematics classroom events. School science and mathematics, 112(7), 420-432.

Jacobs, V. R., Lamb, L. L. C., \& Philipp, R. A. (2010). Professional noticing of children's mathematical thinking. Journal for Research in Mathematics Education, 41(2), 169-202.

Kainulainen, M., McMullen, J., \& Lehtinen, E. (2017). Early developmental trajectories towards the concept of rational numbers. Cognition and Instruction, 35(1), 4-19.

Kaiser, G., Blömeke, S., Koenig, J., Busse, A., Doehrmann, M., \& Hoth, J. (2017). Professional competencies of (prospective) mathematics teachers-cognitive versus situated approaches. Educational Studies in Mathematics, 94(2), 161-182.

Major, L., \& Watson, S. (2017). Using video to support in-service teacher professional development: the state of the field, limitations and possibilities. Technology, Pedagogy and Education, 27(1), 49-68. https://oi. org/10.1080/1475939X.2017.1361469.

Mason, J. (2011). Noticing. In Sherin, M., Jacobs, V. \& Phillip, R. (Eds.) Mathematics teacher noticing: seeing through teachers' eyes (p. 35-50). Taylor and Francis. Kindle Edition.

Mattinen, A. (2006). Huomio lukumääriin. Tutkimus 3-vuotiaiden lasten matemaattisten taitojen tukemisesta päiväkodissa. (Unpublished doctoral thesis, University of Turku, Turku, Finland)

McIntyre, N. (2016). Teach at first sight: expert teacher gaze across two cultural settings. PhD thesis, University of York. Retrieved 11.7.2019 from http://etheses.whiterose.ac.uk/15408/.

McIntyre, N. A., Mainhard, M. T., \& Klassen, R. M. (2017). Are you looking to teach? Cultural, temporal and dynamic insights into expert teacher gaze. Learning and Instruction, 49, 41-53.

McIntyre, N. A., Jarodzka, H., \& Klassen, R. M. (2019). Capturing teacher priorities: using real-world eyetracking to investigate expert teacher priorities across two cultures. Learning and Instruction, 60, 215-224.

McMullen, J., Laakkonen, E., Hannula-Sormunen, M., \& Lehtinen, E. (2015). Modeling the developmental trajectories of rational number concept(s). Learning and Instruction, 37, 14-20. https://doi.org/10.1016/j. learninstruc.2013.12.004.

Merenluoto, K., \& Lehtinen, E. (2004). Number concept and conceptual change: towards a systemic model of the processes of change. Learning and Instruction, 14(5), 519-534. https://doi.org/10.1016/j. learninstruc.2004.06.016.

Miller, K.F. (2011). Situation awareness in teaching. In Sherin, M., Jacobs, V. \& Phillip, R. (Eds.) Mathematics Teacher Noticing: Seeing Through Teachers' Eyes (p. 51-65). Taylor and Francis. Kindle Edition.

Newton, K. J. (2008). An extensive analysis of preservice elementary teachers' knowledge of fractions. American Educational Research Journal, 45(4), 1080-1110. https://doi.org/10.3102/0002831208320851.

Obersteiner, A., Van Dooren, W., Van Hoof, J., \& Verschaffel, L. (2013). The natural number bias and magnitude representation in fraction comparison by expert mathematicians. Learning and Instruction, 28, 64-72. https://doi.org/10.1016/j.learninstruc.2013.05.003.

Seidel, T., \& Stürmer, K. (2014). Modeling and measuring the structure of professional vision in preservice teachers. American Educational Research Journal, 51(4), 739-771. https://doi.org/10.3102 /0002831214531321.

Sherin, M. G., \& Han, S. Y. (2004). Teacher learning in the context of a video club. Teaching and Teacher Education, 20(2), 163-183. https://doi.org/10.1016/j.tate.2003.08.001.

Sherin, M. G., \& van Es, E. A. (2009). Effects of video club participation on teachers' professional vision. Journal of Teacher Education, 60(1), 20-37. https://doi.org/10.1177/0022487108328155.

Sherin, M. G., Russ, R. S., Sherin, B. L., \& Colestock, A. (2008). Professional vision in action: an exploratory study. Issues In Teacher Education, 17(2), 25-46.

Shoenfelt, A. H. (2011). Noticing matters. A lot. Now what? In Sherin, M., Jacobs, V. \& Phillip, R. (Eds.) Mathematics teacher noticing: seeing through teachers' eyes (p. 223-238). Taylor and Francis. Kindle Edition.

Shvarts, A. (2018). Joint attention in resolving the ambiguity of different presentations: a dual eye-tracking study of the teaching-learning process. In N. Presmeg, L. Radford, W. M. Roth, \& G. Kadunz (Eds.), Signs of signification. Semiotics in Mathematics Education Research (pp. 73-102). Cham: ICME-13 Monographs Springer.

Siegler, R. S., Fazio, L. K., Bailey, D. H., \& Zhou, X. (2013). Fractions: the new frontier for theories of numerical development. Trends in Cognitive Science, 17(5), 13-19. https://doi.org/10.1111/desc.12155. 
Stahnke, R., Schueler, S., \& Roesken-Winter, B. (2016). Teachers' perception, interpretation, and decisionmaking: a systematic review of empirical mathematics education research. ZDM, 48(1-2), 1-27.

Star, J. R., \& Strickland, S. K. (2008). Learning to observe: using video to improve preservice mathematics teachers' ability to notice. Journal of Mathematics Teacher Education, 11(2), 107-125. https://doi. org/10.1007/s10857-007-9063-7.

Stockero, S. L., Rupnow, R. L., \& Pascoe, A. E. (2017). Learning to notice important student mathematical thinking in complex classroom interactions. Teaching and Teacher Education, 63, 384-395. https://oi. org/10.1016/j.tate.2017.01.006.

Stürmer, K., Könings, K. D., \& Seidel, T. (2013a). Declarative knowledge and professional vision in teacher education: effect of courses in teaching and learning. British Journal of Educational Psychology, 83(3), 467483. https://doi.org/10.1111/j.2044-8279.2012.02075.x.

Stürmer, K., Seidel, T., \& Schäfer, S. (2013b). Changes in professional vision in the context of practice. Gruppendynamik und Organisationsberatung, 44(3), 339-355.

Stürmer, K., Seidel, T., \& Holzberger, D. (2016). Intra-individual differences in developing professional vision: preservice teachers' changes in the course of an innovative teacher education program. Instructional Science, 44(3), 293-309.

Stürmer, K., Seidel, T., Müller, K., Häusler, J., \& Cortina, K. S. (2017). What is in the eye of preservice teachers while instructing? An eye-tracking study about attention processes in different teaching situations. Zeitschrift für Erziehungswissenschaft, 20(1), 75-92.

Tobii, A. B.. (2016). User's manual Tobii Pro Glasses 2. Version 1.1.3, 12/2016. Retrieved 11.7.2019 from https://www.tobiipro.com/siteassets/tobii-pro/user-manuals/tobii-pro-glasses-2-user-manual.pdf/?v = 1.1.3.

Tobii Pro, A. B.. (2019). Tobii Pro Lab User's Manual. Version 1.118.1, 06/2019. Retrieved 4.7.2019 from https://www.tobiipro.com/learn-and-support/downloads-pro/.

Vamvakoussi, X. \& Vosniadou, S. (2004). Understanding the structure of the set of rational numbers: a conceptual change approach. Learning and Instruction, 14(5), 453-467.

Vamvakoussi, X., Van Dooren, W., \& Verschaffel, L. (2012). Naturally biased? In search for reaction time evidence for a natural number bias in adults. The Journal of Mathematical Behavior, 31(3), 344-355.

Van den Bogert, N., van Bruggen, J., Kostons, D., \& Jochems, W. (2014). First steps into understanding teachers' visual perception of classroom events. Teaching and Teacher Education, 37, 208-216.

Van Dooren, W., Lehtinen, E., \& Verschaffel, L. (2015). Unraveling the gap between natural and rational numbers. Learning and Instruction, 37, 1-4. https://doi.org/10.1016/j.learninstruc.2015.01.001.

van Es, E. A., \& Sherin, M. G. (2002). Learning to notice: scaffolding new teachers' interpretations of classroom interactions. Journal of Technology and Teacher Education, 10(4), 571-596.

van Es, E. A., \& Sherin, M. G. (2008). Mathematics teachers' "learning to notice" in the context of a video club. Teaching and Teacher Education, 24(2), 244-276. https://doi.org/10.1016/j.tate.2006.11.005.

van Gog, T., Paas, F., van Merriënboer, J. J. G., \& Witte, P. (2005). Uncovering the problem-solving process: cued retrospective reporting versus concurrent and retrospective reporting. Journal of Experimental Psychology, 11(4), 237-244. https://doi.org/10.1037/1076-898X.11.4.237.

Vosniadou, S., Pnevmatikos, D., Makris, N., Lepenioti, D., Eikospentaki, K., Chountala, A., \& Kyrianakis, G. (2018). The recruitment of shifting and inhibition in on-line science and mathematics tasks. Cognitive Science, 42(6), 1860-1886. https://doi.org/10.1111/cogs.12624.

Weber, K. E., Gold, B., Prilop, C. N., \& Kleinknecht, M. (2018). Promoting pre-service teachers' professional vision of classroom management during practical school training: effects of a structured online- and videobased self-reflection and feedback intervention. Teaching and Teacher Education, 76, 39-49.

Wolff, C. E., van den Bogert, N., Jarodzka, H., \& Boshuizen, H. P. A. (2015). Keeping an eye on learning: differences between expert and novice teachers' representations of classroom management events. Journal of Teacher Education, 66(1), 68-85. https://doi.org/10.1177/002248711454981.

Wolff, C. E., Jarodzka, H., \& Boshuizen, H. P. (2017). See and tell: differences between expert and novice teachers' interpretations of problematic classroom management events. Teaching and Teacher Education, $66,295-308$.

Wolff, C. E., Jarodzka, H., van Den Bogert, N., \& Boshuizen, H. P. A. (2016). Teacher vision: expert and novice teachers' perception of problematic classroom management scenes. Instructional Science, 44(3), $243-265$. https://doi.org/10.1007/s11251-016-9367-z.

Publisher's Note Springer Nature remains neutral with regard to jurisdictional claims in published maps and institutional affiliations. 